\title{
Кореферентные структуры, используемые для представления экономических субъектов в медийном дискурсе
}

\author{
Сергей Ключенович (Минск)
}

\begin{abstract}
The subject of study in the article is the discourse specifics of representation of economic entities in German newspaper and magazine texts of the last two decades. The purpose of the analysis is to elucidate the factors that stimulate univerbation in connection with the generation and textual integration of co-referential structures different in genesis, structural properties, semantic characteristics and stylistic potential.

The study, conducted on the basis of a functional-communicative approach to language, relies on methods and results of studies on text linguistics considering text as a whole structuralsemantic unit.

Conclusions. 1) Mentioning of a company name is accompanied by integration of the univerb indicating the relevant industry into the text. Along with a two-member chain of co-referential nominations, a three-member chain is also possible (the location of a company is mentioned). 2) Co-referential pairs of the type "company name - collective designation of employees according to headquarters location" (Siemens - Münchener) are characteristic, which demonstrates the lability of univerb toponym semantics. 3) The integration of a proper name into the text requires the usage of characterizing common nouns in order to prepare the reader for the perception of unique names, which is a factor motivating univerbation. 4) Synthetic compounds of the nomina agentis type (Autobauer, Stromversorger) are widely used to describe the kind of activity of an enterprise. In such cases a lexeme with the expected semantics is eliminated (Unternehmen 'company', Konzern 'concern' etc.). The reduction of the base lexeme of a compound as well as representation of the verb lexeme in the form of nomen agentis has an impact on the semantics and stylistics of the univerb.

The results of the study can be used both in research activities on problems of word-formation, semantics and in the training of business translators.
\end{abstract}

\section{1 Введение}

Анализ собранного нами эмпирического материала выявил сосуществование в современном немецком языке в определенный момент параллельных способов номинации одного и того же референта, что, на наш взгляд, вполне можно считать проявлением «динамической синхронии» (Якобсон 1985). На возможность «разноименности денотата» в современном немецком языке на примере обиходной 
лексики указывал Девкин (1979: 186), проблему множественности кореферентных имен разрабатывала также Шемчук (2006). Полиномия (многоименность) может возникать, например, в результате использования синонимов, вариантов, параллелей.

Важно обратить внимание на то, что в своем докторском исследовании Шемчук рассматривает переименование как языковое явление, фокусируясь на системном изучении результатов модернизации словарного состава языка, привлекая для этих целей материал из лексикографических источников. В нашем же исследовании релевантным становится рассмотрение полиномии сквозь призму текста, с точки зрения выстраивания его структуры, прочерчивания внутритекстовых связей.

Лингвисты характеризуют текст как целостное в смысловом отношении образование (“Bedeutungsganzes”; Greimas 1971: 45), как «информационное и структурное единство» (Валгина 2003: 43; Тураева 2015: 11), рассматривая при этом связность как один из «основных конструктивных признаков текста» (Валгина 2003: 43; Филиппов 2007). Примечательно, что «связность в самом общем плане можно определить через повтор: последовательность знаков расценивается как связная, так как имеет место повторяемость различных знаков, их форм, а также смыслов» (Земская et al. 2012: 99). Повторяемость смыслов как фактор обеспечения семантической когерентности текста может достигаться не только благодаря прямому повтору лексем в тексте, но и благодаря повтору, основанному на варьировании ("variierte Wiederholung" (Heinemann/Heinemann 2002: 73), “variierende Wiederholung” (Gansel/Jürgens 2007: 41)) в результате использования синонимов, гиперонимов, иносказаний. Вследствие этого имеет место реккуренция определенных сем в различных лексических единицах по ходу развертывания текста, в результате чего, по А. Ж. Греймасу, возникает изотопия, в основе которой лежит семантическая эквивалентность между определенными лексемами, включенными в текст (cf. Greimas 1971).

Возникновение кореферентных структур, расширение изотопических цепочек не в последнюю очередь стимулируется словосложением, которое представляет собой исключительно продуктивный способ словообразования в немецком языке и изобильно насыщает полилексемными универбами современный дискурс. Павлов, известный своими работами по словосложению в немецком языке, писал, что композитная техника производства слов «широко участвует в речевых процессах [...] применительно к ситуативным задачам речевой коммуникации» (Павлов 1985: 275). На фоне рассмотрения того, как полилексемные универбы включаются в тексто-речевое воплощение, чётко осознаётся синтагматический статус производных, живой, динамический характер самого типа композитного словообразования в функционировании современного немецкого языка.

\section{2 Представление компаний, концернов и иных юридических лиц в газетном тексте}

Анализ эмпирического материала позволил выявить определенную дискурсивную специфику, связанную с представлением экономических субъектов в газетножурнальном тексте. Проиллюстрируем это на примерах из нашей картотеки. 
Заголовок: So will Nestlé ${ }^{1}$ bis 2050 klimaneutral werden

Текст: Der Nahrungsmittelriese steht im Visier von Umweltschützern und stößt jährlich Millionen Tonnen Treibhausgas aus.

(Brächer 2019).

[‘Так «Нестле» планирует стать климатически нейтральным к 2050 году. Гигант пищевой промышленности находится под пристальным вниманием экологов в связи с тем, что ежегодно выбрасывает миллионы тонн парниковых газов в атмосферу.']

Как свидетельствует приведённый фрагмент, упоминание названия концерна сопровождается последующим введением в текст универба с указанием соответствующей отрасли.

В приводимом ниже примере полиномия характеризуется большей разветвлённостью.

Предтекст: Heckler \& Koch hat einen millionenschweren Vertrag mit dem britischen Verteidigungsministerium abgeschlossen. Der Waffenhersteller soll die Sturmgewehre der britischen Armee modernisieren.

[“«Хеклер \& Кох» заключил миллионный контракт с министерством обороны Великобритании. Производитель оружия будет модернизировать автоматические винтовки британской армии.']

Текст: Der hoch verschuldete Waffenhersteller Heckler \& Koch hat einen wichtigen Großauftrag an Land gezogen. Man habe einen bis zu 65 Millionen Pfund (73 Millionen Euro) schweren Vertrag mit dem Verteidigungsministerium Großbritanniens abgeschlossen, wie das Unternehmen aus Oberndorf in Baden-Württemberg am Freitag mitteilt.

(Handelsblatt 2019)

['Имеющему большие долги производителю оружия «Хеклер \& Кох» удалось получить крупный заказ. Речь идёт о контракте на 65 миллионов фунтов (73 миллиона евро) с министерством обороны Великобритании, как сообщила компания из Оберндорфа в Баден-Вюртемберге в пятницу.']

Здесь полиномия реализуется уже не в двухчленной цепочке кореферентных номинаций, как в предыдущем примере, а в трёхчленной цепочке (Heckler \& Koch - Waffenhersteller - das Unternehmen aus Oberndorf in Baden-Württemberg), т. е. модель представления компании в тексте включает в качестве своих звеньев помимо названия фирмы и сферы её деятельности также и местоположение предприятия.

Следующий пример также заслуживает внимания.

Заголовок: RWE und Siemens bauen größten Windpark der Welt

['RWE и «Сименс» строят самый большой ветропарк в мире']

Текст: RWE, Siemens [...] ziehen einen der größten Windparks auf Seehoch. Der Essener Energiekonzern, der Münchner Anlagenbauer [...] haben ein Gemeinschaftsunternehmen gegründet, das für über zwei Milliarden Euro einen Windpark vor der Küste von Wales errichten soll.

(dpa/Reuters 2010)

['RWE, «Сименс» [...] возводят один из самых крупных ветропарков в море. Эссенский энергетический концерн, мюнхенский производитель [промышленного] оборудования [...]

\footnotetext{
1 Здесь и в последующих текстовых примерах выделено мною - С. К.
} 
учредили совместное предприятие, которое планирует соорудить за два миллиарда евро ветропарк у побережья Уэльса.']

Особенность этого фрагмента заключается в том, что здесь речь идет сразу о двух концернах. Номинативные цепочки RWE - der Essener Energiekonzern, Siemens - der Münchner Anlagenbauer отмечены структурно-семантической симметричностью: два параметра (местоположение и отрасль) совмещаются в одной позиции. Надо полагать, что топоним и название отрасли помогают обеспечить прочерчивание синонимических связей через текст к названию соответствующего концерна, что особенно актуально, когда изложение предполагает дифференциацию компаний при их последующей номинации в тексте.

\section{3 Обновление значения как способ словообразования. Контекстуально- смысловая универбация}

В приводимом ниже фрагменте можно наблюдать ещё один пример полиномии.

Volkswagen hat im August 6,6 Prozent weniger Autos ausgeliefert als im Jahr zuvor. Im Juli lagen die Wolfsburger noch nur knapp hinter den Vorjahreszahlen. [...] Im Juli dieses Jahres hatten die Auslieferungen des größten Autokonzerns verglichen mit dem Vorjahr nur noch um 0,2 Prozent im Minus gelegen.

(Handelsblatt 2020)

['«Фольксваген» отгрузил в августе на 6,6 \% меньше автомобилей, чем годом ранее. В июле вольфсбуржцам не хватало ещё совсем немного для достижения прошлогодних показателей. [...] Снижение объёмов отгрузки самого крупного автоконцерна в июле этого года, по сравнению с аналогичным периодом прошлого года, составляло ещё всего лишь $0,2 \%$.']

Этот случай интересен тем, что местоположение штаб-квартиры концерна манифестируется производным Wolfsburger 'вольфсбуржцы'. Такая лаконичность обусловливает в условиях кореферентности «обновление значения» (Ефимов 1953: 323) словарного слова в результате «обозначения нового понятия путём нового применения старого слова» (Щерба 1915: 80). Таким словарным словом в нашем случае следует считать Wolfsburger в значении 'жители Вольфсбурга'. В тексте же можно наблюдать несколько иное значение, а именно 'сотрудники головного предприятия «Фольксвагена» в г. Вольфсбург'.

В данной связи нельзя не согласиться и с Г. Паулем, который считает, что «возможность [...] изменений значений вытекает из того факта, что значение, приобретаемое словом в каждом отдельном акте употребления, не обязательно должно совпадать со значением, присущим слову как таковому согласно узусу» (Пауль 1960: 93-94). Окказиональное значение, согласно Г. Паулю, «чаще всего богаче узуального по содержанию и у́же его по объему» (ibd.: 94). При этом примечательно, что «будучи употреблено окказионально в соответствующем производном значении, слово может быть понято без содействия основного значения» (ibd.: 96-97), или, как это сформулировано в оригинале, «ohne Zuhilfenahme der Grundbedeutung» (Paul 1920: 78) 'без обращения к основному значению'. 
В свете сказанного небезынтересно мнение Г. В. Пана, который считает, что «о термине «сложное слово» или «производное слово» можно говорить с точки зрения их строения, а о понятии «универб» - с позиции сочетания слов (лексем), скрывающихся за цельной единицей» (Пан 1978: 16). Янко-Триницкая говорит о «включении»как «расширении значения слова, которое осуществляется за счет семантики другого слова, не получающей в данном слове отдельного морфемного выражения» (Янко-Триницкая 2001: 375). Эту же мысль развивает и Дозорова, которая говорит об особом характере мотивации универба: «по составу компонентов она не может быть отнесена ни к однословной, ни к многословной мотивации в чистом виде. Это особый тип «включенной» мотивации: участие формально не выраженного, но семантически значимого компонента в структуре производного» (Дозорова 2018: 7).

Важно отметить, что «необходимым условием существования окказионального значения является соответствующая речевая ситуация и/или соответствующий контекст. Синсемантия слов с окказиональным значением имеет самую высокую степень, автосемантия же таких слов равна нулю» (Ханпира 1972: 291). Схожее мнение высказывает и Тимошина, рассматривая весь спектр «несистемных значений», к которым она относит «все те значения, которые не отражаются в традиционных толковых словарях, не общеизвестны (ограничены в своём функционировании) и контекстуально зависимы (обусловлены)» (Тимошина 2013: 40). Проиллюстрируем это на конкретных текстовых фрагментах из нашей картотеки.

1. Grund des jetzigen Optimismus ist, dass viele Unternehmen ihre Strukturen nachhaltig umbauen. So konzentriert sich Siemens auf gewinnträchtige Bereiche. Nach dem Verkauf der Handysparte lagerten die Münchener die ebenfalls angeschlagene Kommunikationssparte in ein Gemeinschaftsunternehmen mit Nokia aus.

(Sommer 2006).

['Причиной сегодняшнего оптимизма является то, что многие компании работают над серьёзной реорганизацией своих структур. Так, «Сименс» сконцентрировался на прибыльных направлениях. После продажи производства мобильных телефонов, мюнхенцы вывели из структуры концерна также испытывающее проблемы телекоммуникационное направление в совместное предприятие с.

«Нокией»'.]

2. Der Brexit ist für BMW seit Jahren ein Dauerthema: Mit Mini und Rolls-Royce haben zwei von drei Marken ihren Sitz in Großbritannien. BMW ist damit einer der größten industriellen Investoren und Exporteure. [...] die Insel ist der viertgrößte Markt für die Münchener.

(Fasse 2020)

['Брекзит - не первый год уже актуальная тема для БМВ: с учётом «Ровера Мини» и «Роллс-Ройса» две марки из трёх производятся в Великобритании. Тем самым БМВ является одним из крупнейших промышленных инвесторов и экспортёров. [...] Альбион - это четвёртый по величине рынок для мюнхенцев'.]

3. „Die Allianz hat den größten Druck, “ heißt es in Finanzkreisen. Denn die Münchner laborieren an den Problemen ihrer Tochter Dresdner Bank, die sie entweder verkaufen oder stärken müssen.

(Bergermann/Hielscher 2008) 
['Страховая компания «Алльянц» испытывает, как считают в финансовых кругах, наибольшее давление. Так как мюнхенцы работают над проблемами своей дочки «Дрезднер банк», которую им придётся или продавать, или укреплять'.]

В каждом из трёх приведённых выше фрагментов можно проследить кореферентные пары одинакового типа: название компании - коллективное обозначение сотрудников компании по принципу местоположения штаб-квартиры (Siemens - Münchener, BMWMünchener, Allianz - Münchner). Все три приведённых примера прекрасно иллюстрируют лабильность семантики топонима-универба, которая каждый раз формируется под влиянием речевой ситуации. Именно присутствие названия соответствующего концерна в тексте, а также одинаковая референтная отнесённость обеих номинаций делает возможной реализацию окказионального значения ('сотрудники концерна «Сименс»', 'сотрудники БМВ', 'сотрудники страховой компании «Алльянц»') в результате включения дополнительных смысловых компонентов конкретизирующего характера на уровне переменной части семантики слова Münchner.

\section{4 Прагматическая адаптация введения собственного имени в медийный текст}

Введение собственного имени в газетно-журнальный текст может требовать от автора использования нарицательных имён характеризующего характера с целью подготовки читателя к восприятию определённых реалий, уникальных названий, незнакомых широкой аудитории. Проиллюстрируем сказанное на примерах.

Bei einer Umfrage des Wirtschaftssenders CNBC...

(Henry 2008)

['B ходе опроса, проведённого телеканалом CNBC, освещающим новости бизнеса...']

Как видим, появление англоязычной аббревиатуры в тексте, предваряется композитом Wirtschaftssender (дословно: ‘бизнес-канал').

Jedes zweite Medikament [...] stammt aus den Labors von Biotechnik-Unternehmen. [...] In dieser Aktie stecken derzeit 21 Beteiligungen, am wichtigsten sind die Branchen-Schwergewichte Actelion aus der Schweiz sowie Celgene, Gilead, Genentech und Vertex aus den USA.

(Thomson Financial Datastream 2008)

['Каждый второй медикамент [...] разрабатывается в лабораториях биотехнологических компаний. [...] Эта акция включает 21 долевое участие, важнее всего такие отраслевые тяжеловесы, как Actelion из Швейцарии, а также Celgene, Gilead, Genentech и Vertex из США.']

В этом фрагменте приводятся названия целого ряда компаний. Для их представления читателю автор использует общую композитную номинацию Branchen-Schwergewichte 'отраслевые тяжеловесы', характеризующую их статус в отрасли. Проследив связи, уходящие в предшествующую часть текста, мы вычленили ещё одно предваряющее упоминание в виде композита Biotechnik-Unternehmen 'биотехнологические компании'. Таким образом, можно заключить, что прагматическая адаптация введения названий компаний осуществляется в данном тексте в два этапа: Biotechnik-Unternehmen $\rightarrow$ Branchen-Schwergewichte, т. е. сначала сообщается, что это компании (как нарицательное имя, объединяющие всех экономических субъектов в этом тексте), параллельно с этим указывается их отраслевая принадлежность, затем характеризуется их статус в отрасли. Как видим, вектор движения в этой цепочке имеет специфицирующую направленность. 
Примечателен и следующий пример.

Bankaktien. Als der Mittelstandsfinanzierer IKB vor einem Jahr über Geschäfte mit faulen USHypotheken stolperte, war die Finanzkrise in Deutschland angekommen.

(Wirtschaftswoche 2008).

['Банковские акции. Когда год назад учреждение, кредитующее средний бизнес, IKB поскользнулось на сомнительных американских ипотеках, это стало моментом прихода финансового кризиса в Германию'. ]

Банк IKB не является ведущим кредитно-финансовым институтом Германии, поэтому его включение в текст требует указания релевантной фоновой информации. Это делается контактно, в непосредственной препозиции с помощью сложнопроизводного универба Mittelstandsfinanzierer (дословно: 'финансист среднего бизнеса'). Надо признать, что такая формулировка, хоть и называет род деятельности, а также бенефициара, не даёт однозначного представления о субъекте, осуществляющем эту деятельность. Помогает в этом упоминание рубрики перед самим текстом (Bankaktien 'банковские акции'). Сведение воедино релевантной информации, распределённой между Bankaktien и Mittelstandsfinanzierer, позволяет интерпретационно выстроить следующую конструкцию банк, кредитующий средний бизнес. В свою очередь, важно обратить внимание, что использованное название рубрики заставило автора искать альтернативу нейтральноофициальному слову Bank для введения в текст собственного имени.

Анализ отобранного эмпирического материала показал, что прагматическая адаптация, как приём, сопровождающий введение собственного имени в текст, является немаловажным фактором, мотивирующим универбацию в тексте.

\section{5 Трансформация значения универба под влиянием контекста}

Собранная картотека эмпирического материала свидетельствует, что для отображения отраслевой принадлежности либо описания сферы деятельности субъекта хозяйствования в немецких газетно-журнальных текстах экономической тематики наряду с собственно композитами (например, Autokonzern, Bauunternehmen, Privatbank) широко используются сложнопроизводные имена семантического класса nomina agentis (Autobauer, Waffenhersteller, Stromversorger, Mittelstandsfinanzierer). Встраиваться в структуру текста они могут как дистантно, так и контактно. Примером дистантного включения имени деятеля может служить следующий фрагмент.

Hat der Kaffeeröster nach Jahren des Niedergangs mit dem neuen Shop-Konzept in HenstedtUlzburg wieder einen Coup gelandet?

(Hielscher 2008: 53).

['После длившегося не один год спада удалось ли производителю кофе (дословно: обжаривателю кофе) снова сорвать куш благодаря новой концепции торговли в ХенштедтУльцбурге?']

Как член цепочки кореферентных номинаций универб Kaffeeröster выполняет в данном тексте функцию синонимии по отношению к концерну «Чибо».

В текстовом фрагменте ниже включение универба Fischzüchter происходит контактно. Здесь функция имени деятеля в тексте иная - предварить малоизвестное широкому кругу читателей название компании Marine Harvest. 
Die meisten seiner Unternehmen, ob Reedereien, Fischzucht oder Ölbohranlagen, haben mit dem Meer zu tun... [...] Fredriksen hält über Investmentgesellschaften in Steuerparadiesen zum Beispiel Anteile an der Reederei Frontline, der größten Öltankerflotte der Erde. Der Fischzüchter Marine Harvest ist ebenfalls weltweiter Branchenprimus.

(Bomsdorf 2008: 78). ['Большинство его фирм, будь то судоходные компании, разведение рыбы или нефтебуровые платформы, связаны с морем... [...] Фредриксен владеет через инвестиционные фонды в налоговых гаванях, например, пакетами акций судоходной компании Frontline, самом крупном танкерном флоте земли. Компания по разведению рыбы (дословно: разводитель рыбы) Marine Harvest также является лидером отрасли.']

Наряду с полилексемными именами деятеля возможны и однолексемные универбы, как в примере ниже.

Auch Volkswagen, Deutsche Telekom und der Versicherer Allianz haben bislang kaum die Möglichkeieten der Globalisierung genutzt.

(Sommer 2006)

['Также «Фольксваген», «Дойче телеком» и страховая компания (дословно: страховщик) «Алльянц» до сих пор практически не использовали возможности глобализации’.]

Очевидно, что в данном случае Versicherer 'страховщик, страхователь' представляет собой усечённо-трансформированный вариант композита Versicherungsanstalt ‘страховая компания'. В двух предыдущих фрагментах ситуация аналогична: имена деятеля Kaffeeröster, Fischzüchter репрезентируют Kafferöstungsfirma 'фирма, занимающаяся обжаркой кофе' и Fischzuchtunternehmen 'компания по разведению рыбы' соответственно. Как видим, в подобных случаях элиминируется и уходит в подразумевание лексема с относительно очевидной и ожидаемой в таких контекстах семантикой (Unternehmen 'компания', Firma 'фирма', Konzern 'концерн', Bank 'банк', Anstalt 'учреждение, заведение, организация'). Формально же представленными остаются уникальные лексемы, отражающие отраслевую принадлежность или сферу деятельности экономического субъекта.

Обращает на себя внимание тот факт, что редукция опорной лексемы композита, а также представление глагольной лексемы в виде имени деятеля не может не повлечь за собой определённых изменений в семантике и стилистике производного. Происходит деперсонификация значения имени деятеля в силу того, что этот универб номинирует в тексте уже не человека, а компанию, фирму и т. п. А следствием этого становится снижение стилистического регистра, так как использование универбированных имён деятеля типа Kaffeeröster, Fischzüchter для обозначения юридических лиц приобретает коллоквиальный характер.

\section{6 Заключение}

На основании проведенного исследования мы считаем возможным сделать следующие выводы.

1. Определенная дискурсивная специфика связана с представлением экономических субъектов в газетно-журнальном тексте. Упоминание названия компании, концерна, как правило, сопровождается последующим введением в текст универба, 
указывающего соответствующую отрасль. Наряду с двухчленной цепочкой кореферентных номинаций возможна также трёхчленная цепочка, когда помимо названия фирмы и сферы её деятельности указывается также и местоположение предприятия или штаб-квартиры концерна.

2. Для экономического газетного дискурса характерны кореферентные пары типа «название компании - коллективное обозначение сотрудников компании по местоположению штаб-квартиры» (Siemens - Münchener, BMW-Münchener). Такие случаи демонстрируют лабильность семантики топонима-универба, которая каждый раз формируется под влиянием речевой ситуации.

3. Введение собственного имени в газетно-журнальный текст требует от автора использования нарицательных имён характеризующего характера с целью подготовки читателя к восприятию названий, незнакомых широкой аудитории. Подобная прагматическая адаптация является немаловажным фактором, мотивирующим универбацию в тексте.

4. Для отображения отраслевой принадлежности либо описания сферы деятельности субъекта хозяйствования в немецких газетно-журнальных текстах экономической тематики наряду с собственно композитами (Autokonzern, Privatbank) широко используются сложнопроизводные имена семантического класса nomina agentis (Autobauer, Stromversorger, Mittelstandsfinanzierer). Встраиваться в структуру текста они могут как дистантно, так и контактно. В подобных случаях элиминируется и уходит в подразумевание лексема с относительно очевидной и ожидаемой в таких контекстах семантикой (Unternehmen 'компания', Firma 'фирма', Konzern 'концерн', Bank 'банк', Anstalt 'учреждение, заведение, организация’). Формально же представленными остаются уникальные лексемы, отражающие отраслевую принадлежность или сферу деятельности экономического субъекта. Редукция опорной лексемы композита, а также представление глагольной лексемы в виде имени деятеля влечёт за собой определённые изменения в семантике и стилистике производного. Происходит деперсонификация значения имени деятеля, следствием которого становится снижение стилистического регистра, так как использование универбированных имён деятеля типа Kaffeeröster, Fischzüchter для обозначения юридических лиц приобретает коллоквиальный характер.

\section{Литература}

Валгина, Нина (2003): Теория текста. Москва: Логос.

Девкин, Валентин (1979): Немецкая разговорная речь: Синтаксис и лексика. Москва: Международные отношения.

Дозорова, Дарья (2018): Структура, семантика и функиии универбатов в современной русской речи: автореферат кандидатской диссертации. Москва: Московский педагогический государственный университет.

Ефимов, Александр (1953): Язык сатиры Салтыкова-Щедрина. Москва: Издательство Московского университета.

Земская, Юлия et al. (2012): Теория текста. 3-е издание. Москва: Флинта Наука.

Павлов, Владимр (1985): Понятие лексемь и проблема отношений синтаксиса и словообразования. Ленинград: Наука. 
Пан, Геннадий (1978): Языковая экономия и коммуникативная насыщенность текстов в прессе ГДР: автореферат кандидатской диссертации. Москва: Московский государственный педагогический институт иностранных языков им. М. Тореза.

Пауль, Герман (1960): Принциипь истории языка. Москва: Издательство иностранной литературы.

Тимошина, Татьяна (2013): Несистемные аспекты семантики слова. Воронеж: Воронежский государственный педагогический университет.

Тураева, Зинаида (2015): Лингвистика текста. Текст: структура и семантика. 4-е издание. Москва: URSS, Либроком.

Филиппов, Константин (2007): Лингвистика текста: Курс лекций. 2-е издание. СанктПетербург: Издательство Санкт-Петербургского государственного университета.

Ханпира, Эрик (1972): “Окказиональные элементы в современной речи”. В: Левин, Виктор (ред.): Стилистические исследования (на материале современного русского языка). Москва, Наука: 245-317.

Шемчук, Юлия (2006): Модернизация существующей лексики современного немецкого языка: автореферат докторской диссертации. Москва: Московский педагогический государственный университет.

Щерба, Лев (1915): Восточнолужицкое наречие. Том 1. Петроград: типография А. Э. Коллинс.

Якобсон, Роман (1985): Избранные работыл. Москва: Прогресс.

Янко-Триницкая, Надия (2001): Словообразование в современном русском языке. Москва: Индрик.

Gansel, Christina/Jürgens, Frank (2007): Textlinguistik und Textgrammatik: Eine Einführung. 2., überarbeitete und ergänzte Auflage. Göttingen: Vandenhoeck \& Ruprecht.

Greimas, Algirdas Julien (1971): Strukturale Semantik. Methodologische Untersuchungen. Braunschweig: Fr. Vieweg \& Sohn.

Heinemann, Margot/Heinemann, Wolfgang (2002): Grundlagen der Textlinguistik: Interaktion - Text - Diskurs. Tübingen: Niemeyer. (=Reihe Germanistische Linguistik 230).

Paul, Hermann (1920): Prinzipien der Sprachgeschichte. 5. Aufl. Halle a. S.: Niemeyer.

\section{Источники примеров}

Bergermann, Melanie/Hielscher, Henryk (2008): „Der Weise aus dem Sorgenland“. Wirtschaftswoche 16: 57-67.

Bomsdorf, Clemens (2008): „Brutal und spendabel“. Wirtschaftswoche 16: 76-78.

Brächer, Michael (2019): „So will Nestle bis 2050 klimaneutral werden“. Handelsblatt. handelsblatt.com/unternehmen/handel-konsumgueter/klimaschutz-so-will-nestle-bis-2050klimaneutral-werden/25009100.html?ticket=ST-12806787-sRCN4sDGKmbdtljyeoha-ap5 [15.09.2019].

dpa/Reuters (2010): „RWE und Siemens bauen größten Windpark der Welt“. Zeit online. zeit.de/wirtschaft/unternehmen/2010-06/siemens-rwe-windpark-wales [06.04.2019].

Fasse, Markus (2020): „No-Deal-Brexit: BMW könnte die Mini-Produktion verlagern“. Handelsblatt. handelsblatt.com/unternehmen/industrie/autobauer-no-deal-brexit-bmw-koenntedie-mini-produktion-verlagern/26724110.html [16.12.2020]. 
Handelsblatt (2020): "Volkswagen verkauft im August wieder weniger Autos". handelsblatt.com/unternehmen/industrie/coronakrise-volkswagen-verkauft-im-august-wieder-weniger-autos/26198982.html?ticket=ST-12894435-u [22.09.2019].

Handelsblatt (2019): „Waffenhersteller Heckler \& Koch modernisiert Sturmgewehre der britischen Armee". handelsblatt.com/unternehmen/industrie/waffenhersteller-heckler-undkoch-modernisiert-sturmgewehre-der-britischen-armee/25014106.html [22.09.2019].

Henry, Andreas (2008): „Hurra, hurra, der Ölpreis steigt!“ Wirtschaftswoche 28: 114.

Hielscher, Henryk (2008): „Ein Hauch von Ikea“. Wirtschaftswoche 28: 53-59.

Sommer, Ulf (2006): „Dax-Konzerne im Höhenflug““. Handelsblatt. handelsblatt.com/unternehmen/industrie/halbjahresbilanz-dax-konzerne-im-hoehenflug/2684354-all.html [01.09.2021].

Thomson Financial Datastream (2008): „Lieber streuen“. Wirtschaftswoche 28: 115.

Wirtschaftswoche (2008): „854 Milliarden vernichtet“. Wirtschaftswoche 28: 118. 